\title{
Comment
}

\section{Reflecting on 'The 2010 U.S. health care reform: approaching and avoiding how other countries finance health care'}

\author{
SCOTT L. GREER* \\ University of Michigan School of Public Health, USA
}

The United States stands out among rich countries for both the size of its health research establishment, and for the manifest problems of its health care system. It might seem like a country that should be particularly interested in learning from health care systems that work better, but it is not. The research establishment is largely parochial in its concerns, and its political elite invokes few foreign references but the specter of a poorly understood NHS (Ehlke, 2011). Optimists say that the situation might be changing as American experts and elites realize the system is imperfect. Mark Peterson has gone so far as to argue that the appearance of international comparisons in American political discourse was a new factor that helped to explain why Obama, unlike his predecessors, managed to push through a comprehensive health care reform (Peterson, 2011). But what kinds of analysis do Americans do when they pay attention to the rest of the world, and what should they do?

Comparative academic analyses of the US health care system mostly fall into two types. On one side, there is a tradition of research in comparative politics that explains why the United States does not have a coherent and universal health system. This is a well-established genre that finds interest groups, weak labor politics, fragmented institutions, racism and path dependency in different configurations explain the American predicament (Hoffman, 2006).

On the other side there is the increasingly voluminous and sophisticated literature comparing health system inputs and outputs, notably including the work of the OECD and Commonwealth Fund. These latter studies are the ones that are infiltrating American (or at least Democratic) thinking, demonstrating over and over again that the United States pays twice as much as other rich states for health care outcomes that are average, and health that is solidly below average (Nolte and McKee, 2011; Schoen et al., 2013).

"Correspondence to: Scott L. Greer, University of Michigan School of Public Health, Ann Arbor, MI 48109-2029, USA. Email: slgreer@umich.edu 
Neither of these literatures treats the United States as a case for comparative health policy analysis, which is why this article is so useful (White, 2012). Most writing about the United States health care sector is so filled with country-specific language and assumptions as to be unhelpful for comparative analysis. Comparisons traditionally run to Canada or the United Kingdom, which are very different political systems with very different health politics and policies (Johnston Conover et al., 2004); they are often better candidates for a most-different systems analysis. A few other systems that more closely resemble the United States in some aspect, and have scholars who write in English, are appearing on the American radar Germany, Singapore and the Netherlands in particular. But even Anglophone countries with politics and policies that have some resemblance to the United States - Ireland, Australia - are essentially invisible in most comparative literature on US health policy.

White's article is one of the best at integrating the United States into comparative health policy analysis. Once he has done it, it seems simple, for example:

The enacted U.S. reform could be described, extremely roughly, as Japanese pooling with

Swiss and American problems at American prices (p. 289).

There are not many better ways to summarize the Affordable Care Act (ACA) in a sentence, but it is only possible if author and reader can draw on enough comparative studies to identify and understand the Japanese and Swiss systems as comparators.

The implicit question behind the article is whether and how the United States might approach other systems. White notes that despite all the sound and fury, the ACA has a very small policy toolkit. It is a thoroughly American approach: its key devices are small payment reforms, a few taxes economists like (e.g. the tax on expensive insurance plans, p. 303), a mishmash of regulations, and a lot of support to various organizational redesign efforts, which White calls the "Aspirational Agenda" (p. 306). The ACA avoids most of the efficacious tools used around the world for cost containment, above all price controls (White, 2011). Comparative experience shows that while many countries express an interest in components of the Aspirational Agenda, belief that changes to delivery will produce cost containment is almost uniquely American. Such a belief system is well suited to a political system that empowers people who do not actually want to have overall costs controlled (Gusmano, 2011).

The key question White's article raises for this reader is whether the ACA is sustainable in its current form, and whether its instabilities point towards more approaching or more avoiding of other countries' experiences.

The biggest issue in answering this question is the way the system redistributes costs. For example, the case for the ACA is partly that health care providers benefit from it (p. 294). Arizona, the last state to join Medicaid, joined when the costs of uncompensated care threatened to drown its hospitals and local governments. Its government had a face-saving waiver of federal law, allowing it to present its 
decision as a conservative achievement (Brecher, 1984). Something similar might be happening in the United States (Jones et al., 2014).

What happens if the system starts to put bigger costs on its payers? These divide into two consequential groups. First, there are the private sector employers. Their decisions about lobbying can be consequential for the fate of US health care policy, but their decisions about the scope and content of coverage for their employees, even more so. As White explains (p. 296-297), the superficially baffling US dependence on employer financing of health care provides an enormous web of poorly understood subsidies - hidden federal subsidies from the tax exemption that make health insurance an attractive vehicle for employee compensation, but also subsidies to the worseoff within firms. It is no wonder that the framers of the ACA were reluctant to unpick this web. Second, there are the public sector payers. White has noted that health policy experts tend not to understand budgeters very well (White, 2013). As is well rehearsed, the United States pays, in public expenditure, about as much per capita as the United Kingdom and gets rather less.

Put together, we can imagine a constituency for price controls, or an 'all-payer' system in which different payers share a price list, as has been done in some US states (McDonough, 1997) and Japan (Campbell and Ikegami, 2008). In other words, governments and firms alike might find that it is in their interests to collaborate on price controls (p. 310).

Will such a coalition arise? It is unclear. Firms can be fickle; the same corporations that encouraged Clinton to save their costs with a health plan abandoned him when managed care under their control seemed to deliver the savings they wanted (Swenson and Greer, 2002). Since then, payers have found it easier to just provide worse insurance when they need to: limited provider networks, restrictions on procedures, less insurance for dependents or part-time workers, etc. There is no guarantee that they will abandon such a strategy when costs bother them, and while the ACA's insurance regulations eliminated some egregious forms of what experts call 'underinsurance', they still leave plenty of scope for very minimal policies.

Equally, there is a chance that the ACA could simply unravel. Against the hypothesis that the ACA will eventually expand in the manner of Medicaid, there is the hypothesis that it will become politically unsustainable and collapse. Naturally, the biggest unknown is the Supreme Court, which eccentrically rewrote the Medicaid expansion already and might proceed to rewrite the mandate and exchange provisions by eliminating subsidies to people in states that do not establish exchanges. If that happens a likely result is that states which expanded Medicaid will establish exchanges - both because their governments are showing pragmatism, and because it would be hard to explain why a state would want to expand Medicaid while cutting off subsidies to working people. This would leave the ACA fully operative in perhaps 30 states, and very dysfunctional in another 20 . Whether the ACA could survive politically as a program for half the country is highly unclear. Its survival would be a top-line agenda item for a 2016 election that is unlikely to produce the unified Democratic rule most likely to fix its problems. 
Even barring political disaster, the ACA is unstable in a way that might undermine it and the whole idea of comprehensive health reform. The Dutch and Swiss experiences do not justify a great faith in mandates (van Ginneken and Swartz, 2013). As White - almost alone - points out, the only real ACA enforcement comes from denying tax credits or refunds. That is a problematic approach, given the incidence of US taxes and the complexity of its personal tax returns (p. 302). The Aspirational Agenda, likewise, is just that - aspirational. The United States has eschewed the international standards of 'concentration of payer power, coordinated payment rules, limits on capital investment and relative administrative simplicity' (p. 305) and instead bet on a more politically palatable farrago of Medicare payment reforms and research. At the moment the ACA is quite affordable because many states did not implement Medicaid expansion and because something, probably the weak economy, is holding down health costs across the board (Altman, 2014). There is no good reason to think that the ACA will be able to hold down costs in the future.

White's article is a very good example of how comparative health policy can illuminate the US system, going beyond both its technically complex parochial literature and broad-brush comparative politics. The Aspirational Agenda, like the virtues of competition, is in the air in the US - but looks much more distinctive and questionable once we notice that no other country entrusts something as crucial as health financing to dysfunctional markets and delivery-system tweaks. Looking at experiences as far apart as Japan and Switzerland, then, identifies the kinds of experiences the United States is letting itself in for and, crucially, the kinds of feedback loops that will shape future policies as employers, payers and others deal with the effects of their reformed system. The promise of comparative health policy research is there: in formulating better questions and then in understanding how parts of systems interconnect. We can hope that White's article inspires more.

\section{Acknowledgment}

I would like to thank Joe White for his comments and thoughts on this paper.

\section{References}

Altman, D. (2014), 'Health cost growth is down, or not. It depends on who you ask', in Kaiser Family Foundation Perspectives. Kaiser Family Foundation, http://kff.org/ health-costs/perspective/health-cost-growth-is-down-or-not-it-depends-who-you-ask/ [31 March 2015].

Brecher, C. (1984), 'Medicaid comes to Arizona: a first-year report on AHCCS', Journal of Health Politics, Policy and Law, 9(3): 411-425.

Campbell, J. C. and I. Naoki (2008), 'The Art of Balance in Health Policy: Maintaining Japan's Low-Cost, Egalitarian System', New York: Cambridge University Press.

Ehlke, D. (2011), 'The political abuse of international health system comparisons', Journal of Health Services Research \& Policy, 16: 187-189. 
Gusmano, M. K. (2011), 'Do we really want to control health care spending?', Journal of Health Politics, Policy and Law, 36(3): 495-500.

Hoffman, B. (2006), 'Tell me again: why is there no National Health Insurance in the United States?', Journal of Health Politics, Policy, and Law, 31(4): 839-848.

Johnston Conover, P., D. Searing and I. Crewe (2004), 'The elusive ideal of equal citizenship: political theory and political Psychology in the United States and Great Britain', Journal of Politics, 66: 1036-1068.

Jones, D. K., P. M. Singer and J. Z. Ayanian (2014), 'The changing landscape of medicaid: practical and political considerations for expansion', JAMA: Journal of the American Medical Association, 311(19): 1965-1966.

McDonough, J. E. (1997), 'Tracking the demise of state hospital rate setting', Health Affairs, 16(1): 142-149.

Nolte, E. and M. McKee (2011), 'Variations in amenable mortality-Trends in 16 high-income nations', Health Policy, 103(1): 47-52.

Peterson, M. A. (2011), 'It was a different time: Obama and the Unique Opportunity for Health Care Reform', Journal of Health Politics, Policy and Law, 36(3): 429-436.

Schoen, C., R. Osborn, D. Squires and M. M. Doty (2013), 'Access, affordability, and insurance complexity are often worse in the United States compared to ten other countries', Health Affairs (Millwood), 2205-2215.

Swenson, P. and S. L. Greer (2002), 'Foul weather friends: big business and health care reform in the 1990s in historical perspective', Journal of Health Politics, Policy and Law, 27(4): 605-638.

van Ginneken, E. and K. Swartz (2013), 'Health insurance exchanges in Switzerland and the Netherlands offer five key lessons for the operations of US exchanges." ', Health Affairs, 32(4): 744-752.

White, J. (2011), 'Prices, volume, and the perverse effects of the variations crusade. Point', Journal of Health Politics, Policy and Law, 36(4): 775-790.

White, J. (2012), 'The 2010 U.S. health care reform: approaching and avoiding how other countries finance health care', Health Economics, Policy and Law, 8(3): 289-315.

White, J. (2013), 'Budget-makers and health care systems', Health Policy, 112(3): 163-171. 